\title{
Intestinal Fibrovascular Nodules Caused by Schistosoma mansoni Infection in Calomys callosus Rengger, 1830 (Rodentia: Cricetidae): a Model of Concomitant Fibrosis and Angiogenesis
}

\author{
Jane A Lenzi/+ , Ester M Mota, Marcelo Pelajo-Machado, Leandro S Vale, Bruno S Vale, \\ Zilton A Andrade*, Henrique L Lenzi
}

Departamento de Patologia, Instituto Oswaldo Cruz-Fiocruz, Av. Brasil 4365, 21045-900 Rio de Janeiro, RJ, Brasil

*Centro de Pesquisas Gonçalo Moniz-Fiocruz, Salvador, BA, Brazil

\begin{abstract}
Human schistosomiasis develops extensive and dense fibrosis in portal space, together with congested new blood vessels. This study demonstrates that Calomys callosus infected with Schistosoma mansoni also develops fibrovascular lesions, which are found in intestinal subserosa. Animals were percutaneously infected with 70 cercariae and necropsied at 42, 45, 55, 80, 90 and 160 days after infection. Intestinal sections were stained for brightfield, polarization microscopy, confocal laser scanning, transmission and scanning electron microscopies. Immunohistological analysis was also performed and some nodules were aseptically collected for cell culture.

Numerous intestinal nodules, appearing from 55 up to 160 days after infection, were localized at the interface between external muscular layer and intestinal serosa, consisting of fibrovascular tissue forming a shell about central granuloma(s). Intranodular new vessels were derived from the vasculature of the external vascular layer and were positive for laminin, chondroitin-sulfate, smooth muscle alpha-actin and FVIII-RA. Fibroblastic cells and extracellular matrix components (collagens I, III and VI, fibronectin and tenascin) comprised the stroma. Intermixed with the fibroblasts and vessels there were variable number of eosinophils, macrophages and haemorrhagic foci.

In conclusion, the nodules constitute an excellent and accessible model to study fibrogenesis and angiogenesis, dependent on S. mansoni eggs. The fibrogenic activity is fibroblastic and not myofibroblastic-dependent. The angiogenesis is so prominent that causes haemorrhagic ascites.
\end{abstract}

Key words: Calomys callosus - Rodentia - Cricetidae - Schistosoma mansoni - intestine - nodules - fibrosis - angiogenesis

Important characteristics of the human chronic schistosomiasis mansoni in portal space pathology are extensive and dense fibrosis, together with well vascularized and often tortuous, thin-walled, dilated, and congested blood vessels, presenting a varicose or angiomatoid appearance (Bogliolo 1954, Andrade 1965). The new vessels have arterial and venous (periductal plexus) origin (Bogliolo 1957, Andrade \& Cheever 1971) and the mechanism of this angiogenesis is still unknown. Otherwise, it has been assumed that hepatic fibrogenesis is related to the activity of fibroblasts, myofibroblasts and Ito cells (Grimaud \& Borojevic 1977, Popper \& Martin 1982). However, to our knowledge, none of the described experimental models presents the concomitant association of fibrosis and angiogenesis related to schistosomal infection (Lichtenberg et al. 1971, Cheever 1987).

In this study we show that the rodent Calomys callosus infected with Schistosoma mansoni develops prominent intestinal fibrovascular nodules which show the concomitance of fibrosis and angiogenesis in periovular reaction.

This work was supported by Fiocruz and CNPq.

${ }^{+}$Corresponding author. Fax: +55-21-2573.8673. E-mail: jlenzi@ioc.fiocruz.br

Received 18 June 2002

Accepted 15 August 2002

\section{MATERIALS AND METHODS}

C. callosus were infected when they were five days old by percutaneous exposure to 70 cercariae of the Belo Horizonte (BH) isolate of S. mansoni (Paraense \& Corrêa $1963,1981)$. The rodents were necropsied at 42 (20 Cc), 45 (30 Cc), 55 (10 Cc), 80 (10 Cc), 90 (30 Cc) and 160 (30 Cc) days after infection. Intestinal samples were prepared according to Swiss roll procedure (Lenzi \& Lenzi 1986) and fixed in Carson's Formalin-Millonig (Carson et al. 1973) and embedded in paraffin. Sections $(5 \mu \mathrm{m})$ for brightfield microscopy were stained with hematoxilin and eosin; PASAlcian Blue, $\mathrm{pH}=1.0$ and 2.5; Lennert's Giemsa, Picrosirius (plus polarization microscopy) (Junqueira et al. 1979), Gomori's Silver Reticulin and resorcin-fuchsin stain with or without oxidation with potassium peroxymonosulfate [Oxone monopersulfate compound (Sigma - 22, 803-6)].

Another set of sections was stained with Masson's trichrome, Evans blue $(5 \mu \mathrm{m})$ (Vale et al. 1997) and phosphomolibdic acid-Picrosirius (PMA-PSR) $(20 \mu \mathrm{m})$ (Dolber \& Spach 1993) stains for confocal laser scanning microscopy (CLSM) (LSM 410, Zeiss) to discriminate eosinophils, elastic and collagen fibers. Three-dimensional reconstructions of images were done with $20 \mu \mathrm{m}$ sections of the intestinal nodules. Sections stained with Alcian blue-Safranine (Strobel et al. 1981, Gomez et al. 1987) were applied to distinguish the mast cell subpopulations by brightfield and confocal (CLSM) microscopies. For electron microscopic examination, sections of the intestinal nodules were fixed in $2.5 \%$ glutaraldehyde buffered with $0.1 \mathrm{M}$ cacodylate and postfixed in $1 \%$ osmium tetroxide, 
dehydrated in graded acetone series and embedded in epoxy resin. Ultra-thin sections were stained with uranyl acetate and lead citrate and observed by an EMS 10 B Zeiss electron microscope.

For scanning electron microscopy (SEM), segments of intestine were fixed in Carson's Formalin-Millonig $(>24 \mathrm{~h})$, desiccated in incubator $\left(37^{\circ} \mathrm{C}, 1 \mathrm{~h}\right)$, and analysed in SEM-low vacuum mode (LEO 435-VP).

Immunohistological analysis of the intestinal nodules were performed on cryostat sections or trypsinized paraffin slides by indirect immunofluorescence or indirect peroxidase labeled extravidin or streptavidin-biotin staining (ExtrAvidin-Peroxidase, Sigma E-2886; anti-mouse polyvalent immunoglobulins biotin conjugate (Sigma, B-2016); anti-rabbit immunoglobulins biotin conjugate (Sigma, B3275). In most of the cryostat sections, after fixation with cold acetone $\left(4^{\circ} \mathrm{C}, 10 \mathrm{~min}\right)$ we used indirect immunofluorescence, blocking of non-specific binding by $1 \%$ bovine serum albumin and $3 \%$ skimmed milk (at room temperature, $30 \mathrm{~min}$ ).

The following primary antibodies were applied: collagen I (rabbit anti-human collagen type I, Institut Pasteur de Lyon, ref. 07.90), collagen III (monoclonal mouse anti-human collagen type III, GIBCO BRL, ref. 12070-017), collagen VI (monoclonal human anti-collagen type VI, American Qualex, ref. M2190), Factor VIII-Related Antigen = FVIII-RA (rabbit anti-human F VIII-RA, DAKO, ref. A082), fibronectin (polyclonal rabbit anti-human fibronectin, DAKO, ref. A245), laminin (polyclonal rabbit anti-mouse laminin, American Qualex, ref. R1990), tenascin (polyclonal rabbit anti-human tenascin, American Qualex, ref. R2230), chondroitin-sulfate (monoclonal mouse antichicken chondroitin sulfate, Sigma, ref. C8035), alpha smooth muscle actin (monoclonal mouse anti-alpha smooth muscle actin, Sigma, ref. A-2547), desmin (monoclonal mouse anti-pig desmin, Sigma, ref. D-1033), vimentin (monoclonal mouse anti-pig vimentin, Sigma, ref. V-6630) and pan-cytokeratin (rabbit anti-bovine muzzle epidermal keratin, American Qualex, ref. R0760). Goat anti-rabbit IgG conjugated to rhodamine (American Qualex, A102RN) and goat anti-mouse $\operatorname{IgG}+\operatorname{IgM}+\operatorname{Ig} A$ conjugated to rhodamine (American Qualex, A157RN) were used as secondary antibodies.

Immunofluorescence-stained samples were analyzed with an LSM 410 Confocal Laser Scanning Microscope (Zeiss, Germany). Digital images of fluorescence were acquired in response to excitation with a Helium/Neon laser (543 nm) (filter setting BP 575-640).

Nodules of three $C$. callosus with 90 days of infection were aseptically collected by mechanical dissection in laminar flow after death of the animals by ether. Isolated nodules were cultivated in six-wells plate, in McCoy's 5A medium (Sigma - M4892), supplemented with $20 \%$ fetal bovine serum and penicillin-streptomycin $(10 \mu \mathrm{l} / \mathrm{ml}$ of total medium) in $5 \% \mathrm{CO}_{2}$ incubator, $37^{\circ} \mathrm{C}$.

\section{RESULTS}

On days 55 up to 160 after infection, $C$. callosus developed prominent and diffuse intestinal subserosal nodules resulting in an overall granulated aspect on the intestinal surface (Figs 1,2). The nodules were translucent with or without hemorrhage (Figs 1,2) and by SEM showed a small pedicle and focal extravasation of red cells (Figs 36). When the nodules were isolated (Fig. 7) and cultivated in cell culture they radially originated from the third day onward, a mesh of fusiform cells (Figs 8,9) that were very similar to the fibroblastic cells seen in paraffin section (Fig. 10). The nodules were composed by central granuloma(s) (Figs 25, 26) surrounded by intense and proliferative fibrovascular tissue (Figs 25-28). The fusiform cells presented prominent and ovoid nucleus, with small nucleolus (Fig. 10), and exhibited vimentin-positive (Figs $23,24)$, desmin and smooth muscle alpha-actin-negative cytoskeleton. Strong deposits of carboxylated proteoglycans at the periphery of the cells, yielded a "tram track" appearance (Fig. 11). The vascular component of the nodules derived from proliferating vessels from the external muscular layer, which were smooth muscle alphaactin (Fig. 13), Factor VIII-RA (Fig. 14), laminin (Figs 15, 16) and chondroitin-sulfate (Fig. 17) positive. Close to the vessels there were aggregates of mast cells, mainly in the base of the nodules (Fig. 18).

The stroma of the nodules was diffusely rich in fibronectin (Fig. 19), collagen VI (Fig. 21), collagens I and III and in proteoglycans (carboxylated > sulfated). Tenascin and interstitial collagens were more intense under the serosal surface (Figs 20, 27, 28). The mesothelial cells were highly cytokeratin-positive and were limited to the serosa without migration toward the interior of the nodules (Fig. 22). The three-dimensional aspect of the interstitial collagens in the stroma of the nodules is shown in the Figs 25-30.

Intermixed with the fibroblasts and vessels there were variable number of eosinophils, and large number of macrophages, sometimes presenting erythrophagocytosis, and containing ferric pigment (Fig. 12).

The ultrastructural study confirmed the presence of macrophages with and/or without erythrophagocytosis (Figs 31, 32), vessels (Fig. 33) and showed active fibroblasts. These presented large and ovoid nucleus with peripheric heterochromatin and prominent nucleolus (Fig. 34); the cytoplasm exhibited abundant and sometimes dilated rough endoplasm reticulum (Figs 34-36). The cells were surrounded by extracellular elements (Figs 31, 32, $34,35)$ and contacts between fibroblasts and macrophages were often seen (Figs 32, 37, 38). Some fibroblasts showed lipid vacuoles in the cytoplasm (Figs 33, 38).

\section{DISCUSSION}

The intestinal nodules represent an exaggerated fibrovascular proliferation around periovular granulomas of $S$. mansoni. They are found at the interface between external muscular layer and intestinal serosa.

The mechanisms of the angiogenesis in the nodules are still unknown. Smith (1961) and Schoefl (1963) claimed that mast cells and histamine are involved in capillary growth during injury. Indeed, we detected, mainly at the root of the nodules, a large number of connective tissue mast cells (CTMC) with safranin-positive granules, reflecting the presence of a highly $\mathrm{N}$-sulfated polysaccharide, likely to be mature heparin (Fig. 18). Moreover, mast cells also release other substances [Adenosine diphosphate 
(ADP), 5-hydroxytryptamine (5-HT) and neutral proteases], and heparin has been repeatedly shown to have an important role in different steps involved in angiogenesis (Hudlická \& Tyler 1986). Azizkhan et al. (1980) showed that heparin released from mast cell stimulates migration of capillary endothelial cells rather than their proliferation. Since migration of endothelial cells is an important factor in angiogenesis, mast cells may play an indirect role in the process, particularly in chronic inflammation. Heparin can also activate proteolytic enzyme degrading the extracellular matrix and can inhibit the proliferation of pericytes (Folkman et al. 1983). Usually pericytes restrain endothelial cell proliferation and differentiation (Orlidge \& D'Amore 1987, Shepro \& Morel 1993).
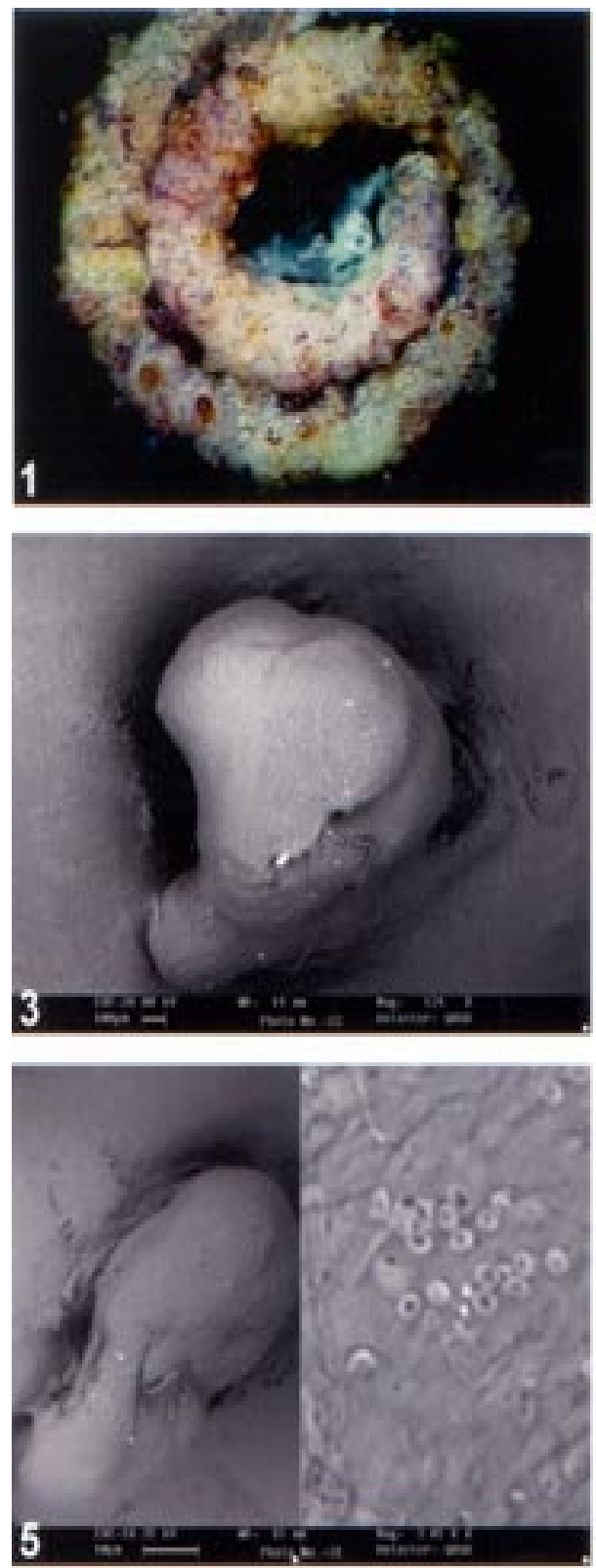

Many cells present in the nodules are capable of producing angiogenic factors when their environment becomes hypoxic or inflammatory, including fibroblasts, monocytes/macrophages (Jackson et al. 1997), and maybe mesothelial cells. In fact, almost every growth factor and cytokine known to regulate angiogenesis can be produced by macrophages (Sunderkotter et al. 1994). Villaschi and Nicosia (1994) showed that fibroblasts could stabilize microvessel sprouts and stimulate angiogenesis from aortic explant cultures, a system that builds on co-culture. Mesothelial cells, in their turn, could produce many inflammatory mediators that have both direct and indirect angiogenic activities, such as: interleukins 1, 6 and 8 (IL1 , IL-6, IL-8), transforming growth factor beta (TGF- $\beta$ ),
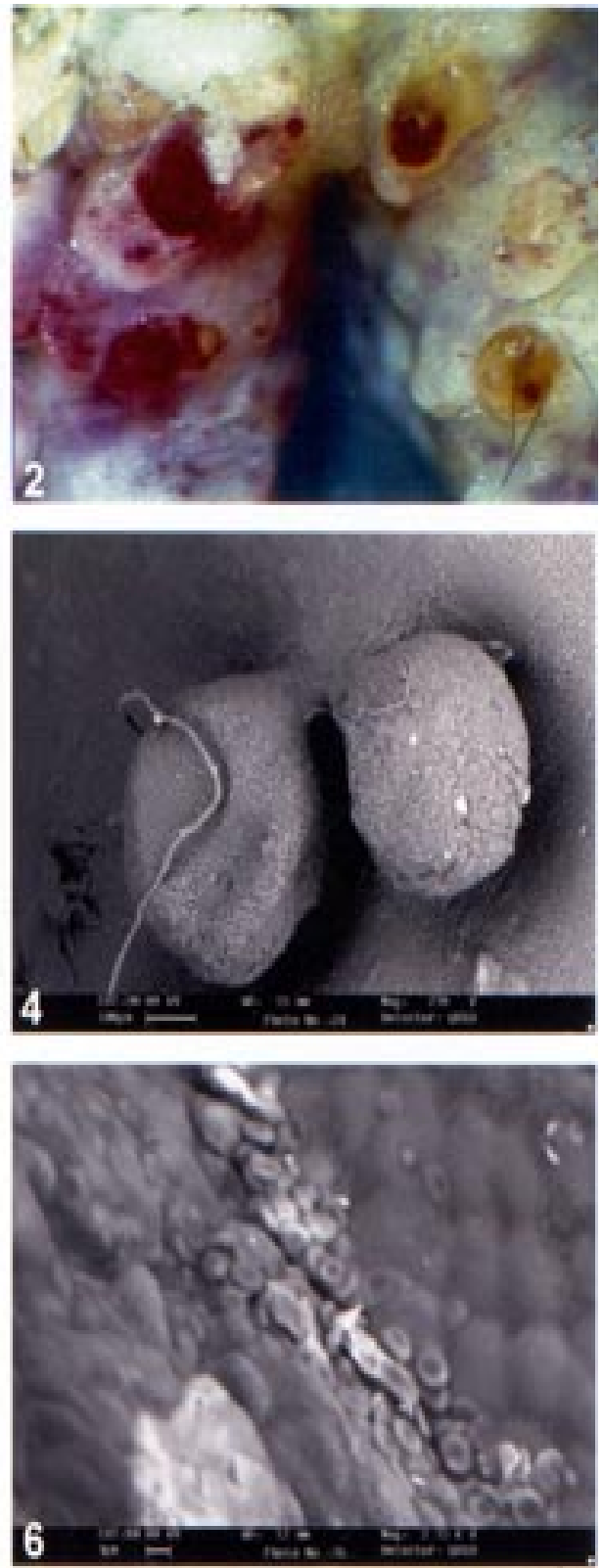

Figs 1,2: macroscopic view of Calomys callosus intestine, 90 days after infection, showing numerous subserosal nodules, many of them with hemorrhage. Figs 3, 4: pedunculated nodules seen with scanning electron microscope (SEM) in low-vacuum mode. Figs 5, 6: details of two nodules covered with a mosaic of mesothelial cells showing focal areas of red cells extravazation (SEM). 
fibroblast growth factor (FGF) and granulocyte macrophage-colony stimulating factor (GM-CSF) (Zeillemaker et al. 1995). Goldsmith (1996) also detected angiogenic activity provoked by omental tissue, and Zhang et al. (1997) showed that vascular endothelial growth factor (VEGF) is the major angiogenic factor in omentum. The mesothelial cells could also up-regulate the fibrogenesis in the nodules, not only by the release of cytokines and growth factors, but also by the secretion of high levels of a plasminogen activator inhibitor PAI-1 (Rheinwald 1989). Human mesothelial cells in culture secrete high levels of this protein $(\mathrm{Mr} 45 \mathrm{KDa})$, which is also produced at equiva- lent levels by endothelial cells and kidney epithelial cells in culture, but at substantially lower levels by fibroblasts, and at almost undetectable levels by many other epithelial cell types (Rheinwald 1989). Plasminogen activator (PA) inhibitor (PAI-1) is an inhibitor of the serpin class of PA and plasmin, together with PAI-2 (60 KDa), protease nexin I (PN-1, $45 \mathrm{KDa}), \alpha 2$-antiplasmin, and aprotinin (7 KDa) (Saksela \& Rifkin 1988, Laiho \& Keski-Oja 1989). Tissue-type PA (TPA, $70 \mathrm{KDa}$ ) is involved in regulating the clotting process, and urokinase-type PA (UPA, 50 $\mathrm{KDa}$ ) is active in fibrinolysis, as well as in biological remodeling, invasive processes, and can cleave fibronectin
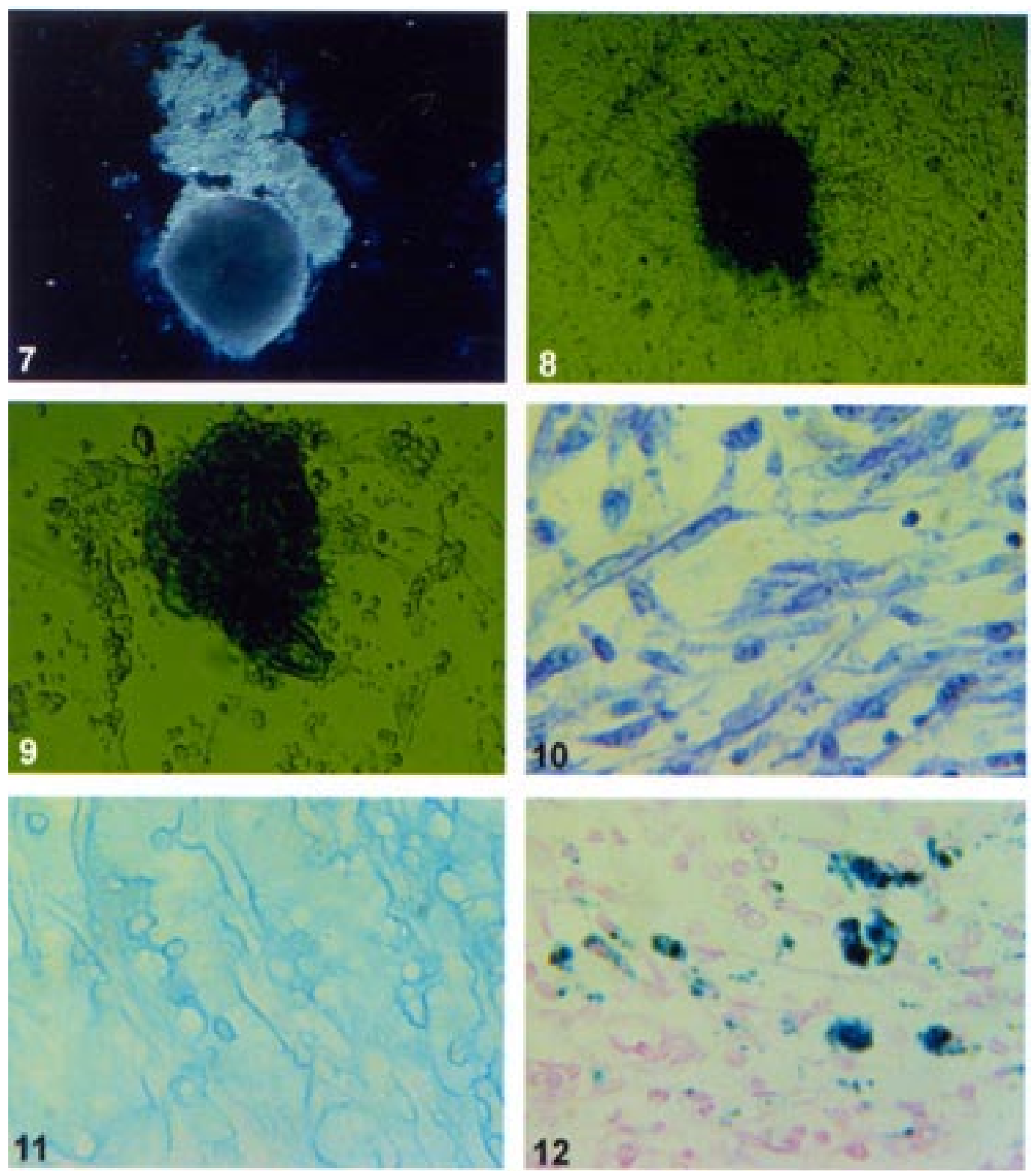

Fig. 7: isolated nodule in time zero of culture. Figs 8, 9: two nodules after three days in culture, showing a radial spreading of fusiform cells (fibroblastic cells). Fig. 10: network of fibroblastic cells with ovoid nucleus, punctiform nucleolus and light blue cytoplasm (Lennert's Giemsa, X 500). Fig. 11: diffuse presence of carboxylated proteoglycans, staining more intensely at the surface of round cells and at the periphery of fibroblastic cells (Alcian Blue, $\mathrm{pH}$ 2.5, X 500). Fig. 12: macrophages full of hemosiderin (Perls staining, X 500). 

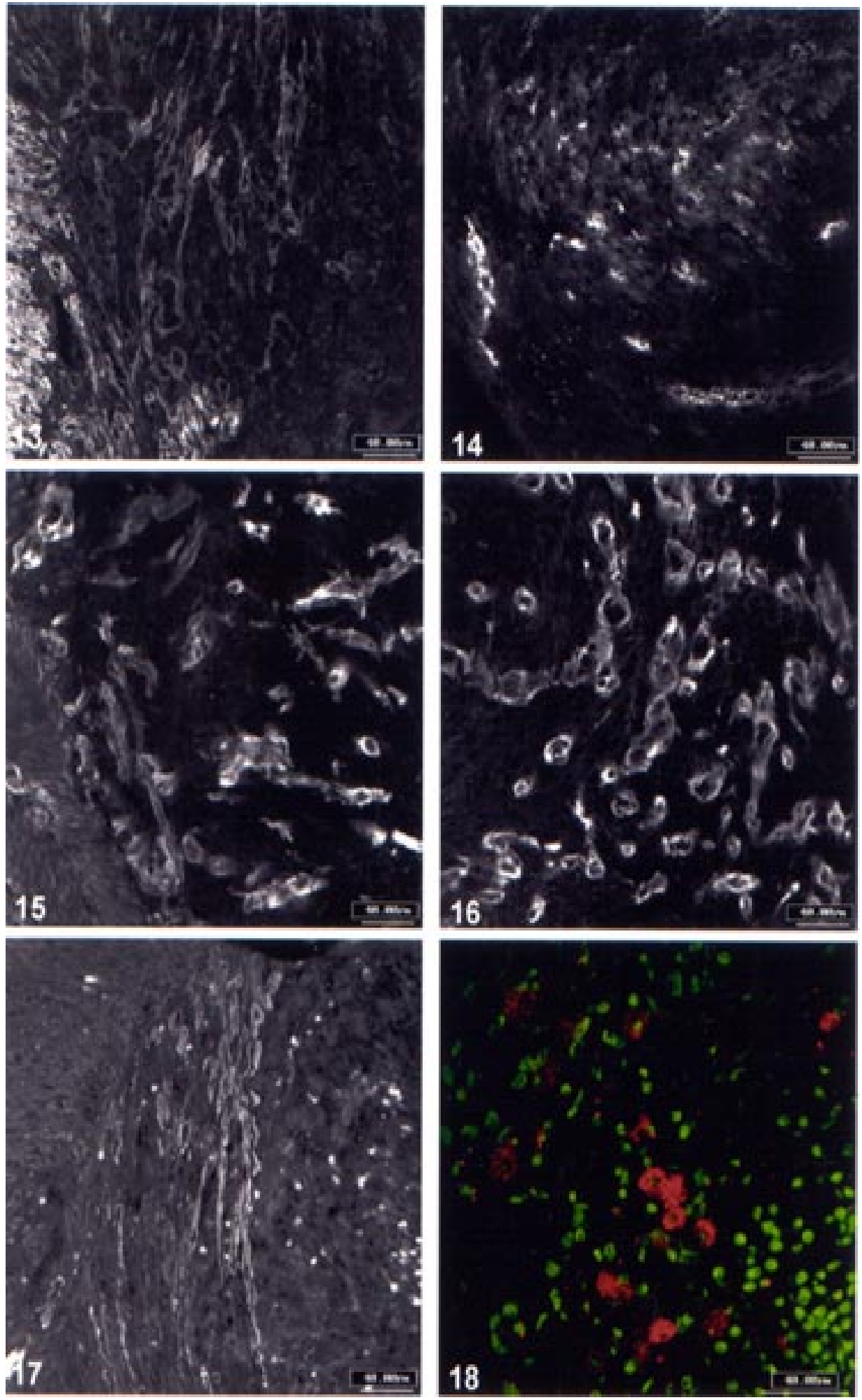

Fig. 13: external muscular layer of small intestine (on the left side), intensely positive to smooth muscle alpha-actin, from where depart new vessels toward the nodule (on the right side) (Smooth muscle alpha-actin, CLSM, bar $=40 \mu \mathrm{m}$ ). Fig. 14: intranodular new vessels labeled with F VIII-RA (CLSM, bar $=40 \mu \mathrm{m})$. Figs 15,16: large number of intranodular new vessels developed by laminin $(\mathrm{CLSM}, \mathrm{bar}=40 \mu \mathrm{m})$. Fig. 17: new vessels at the base of a nodule, close to the external muscular layer of small intestine, presenting their walls positive to chondroitin-sulfate $(\mathrm{CLSM}$, bar $=40 \mu \mathrm{m})$. Fig. 18: mast cells, stained in red, localized at the base of a nodule. The nuclei of other cells were digitally stained in red (Alcian blue-Safranine, CLSM, Lasers Ar $488 \mathrm{~nm}$ e He/Ne $543 \mathrm{~nm}$ and filters BP 515-565 and LP 570, bar = $40 \mu \mathrm{m}$ ). 

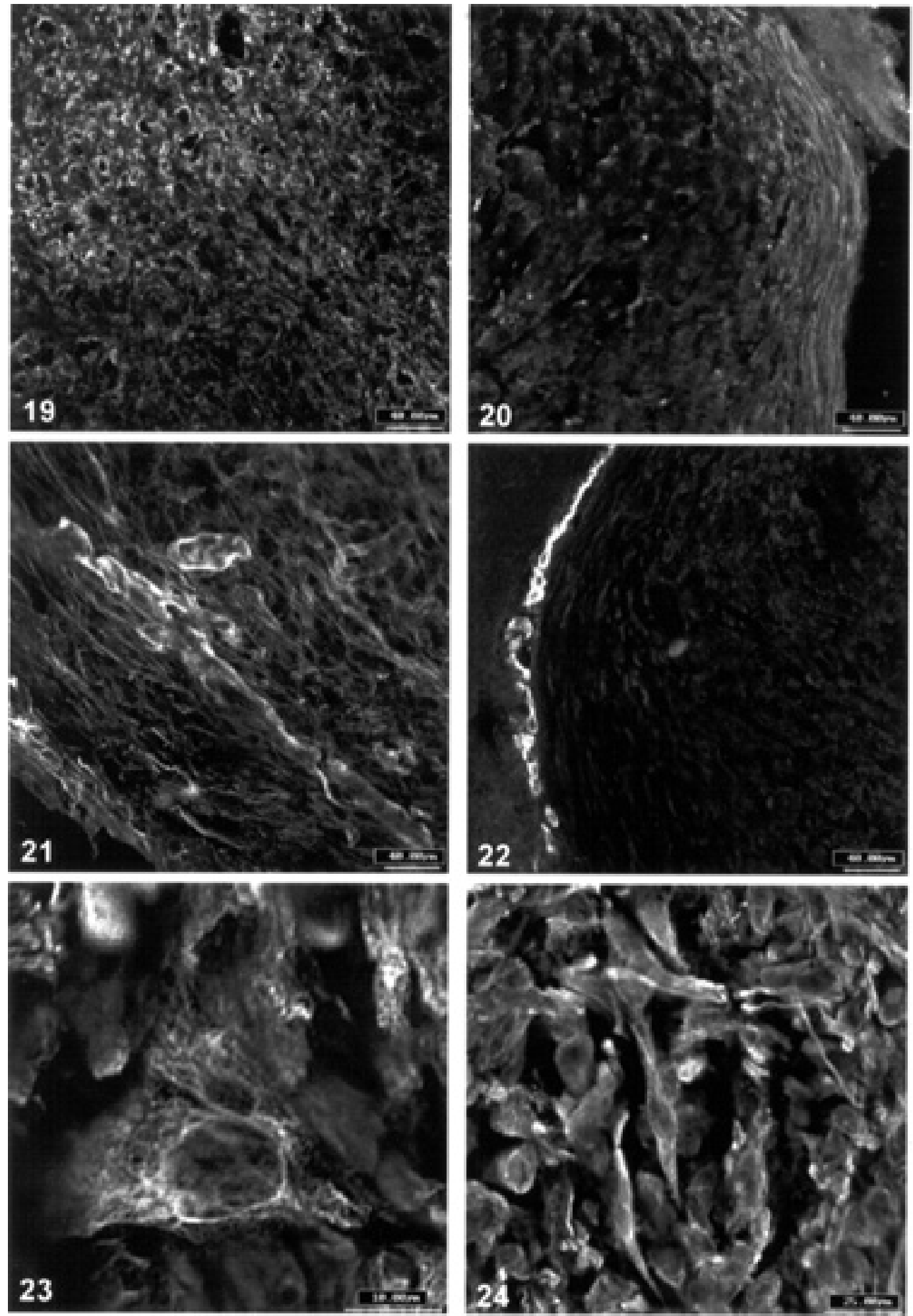

Fig. 19: fibronectin diffusely spread all over the surface of a nodule (CLSM, bar $=40 \mu \mathrm{m})$. Fig. 20: band of tenascin deposit close to the mesothelial surface $(C L S M, b a r=40 \mu \mathrm{m})$. Fig. 21 : fine texture of collagen VI being more intense around some vessels $($ CLSM, bar $=40 \mu \mathrm{m})$. Fig. 22: monolayer of mesothelial cells covering the surface of a nodule highly positive to pan-cytokeratin (CLSM, bar $=40 \mu \mathrm{m})$. Fig. 23 : details of the cytoplasm of some fibroblasts rich in vimentin-positive cytoskeleton (CLSM, bar $=10 \mu \mathrm{m}$ ). Fig. 24: transversal and longitudinal section of vimentin-positive fibroblast (CLSM, bar $=25 \mu \mathrm{m})$. 

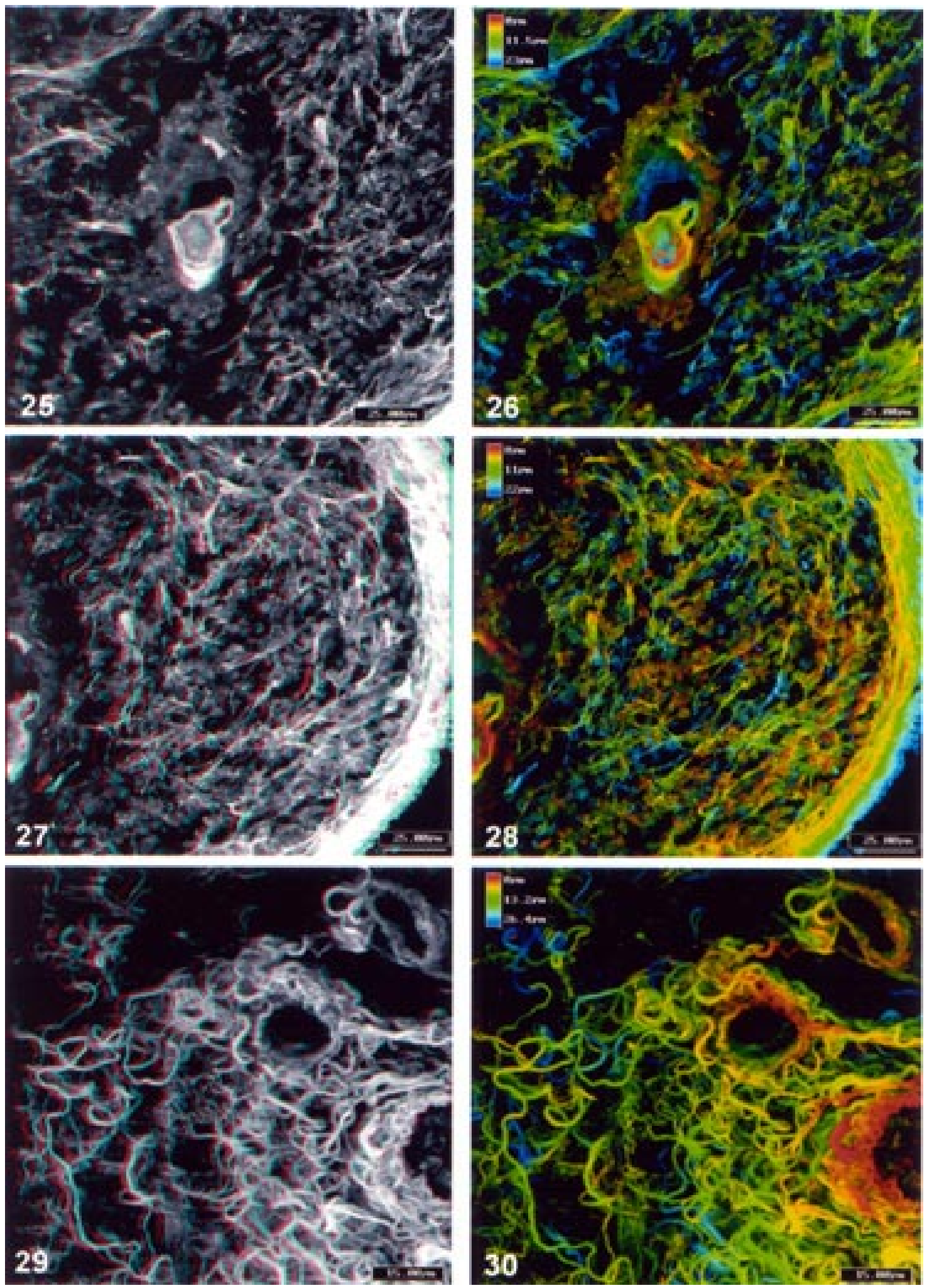

Figs 25, 27, 29: three-dimensional aspect of the collagenic mesh in three different nodules. (special red/green eye glass is required). The figure 25 is centered by a granuloma [(CLSM, bar $=25 \mu \mathrm{m}$ (Figs 25, 27); bar $=15 \mu \mathrm{m}$ (Fig. 29)]. Figs 26, 28, 30: depth-code of the Figs 25 , 27 and 29 (CLSM). 
and plasminogen (Alexander \& Werb 1991). Then the PAI1 secretion can promote the accumulation of some stromal components in the nodules, by interference on extracellular matrix degradation.

Parasite-derived products can also take part in the angiogenesis phenomenon. In fact, $S$. mansoni soluble egg antigen (SEA), in the absence of inflammatory cells, can stimulate proliferation of human umbilical vein endothelial cells (HUVE) in vitro (Freedman \& Ottesen 1988). This effect appears to be due to up-regulation of human

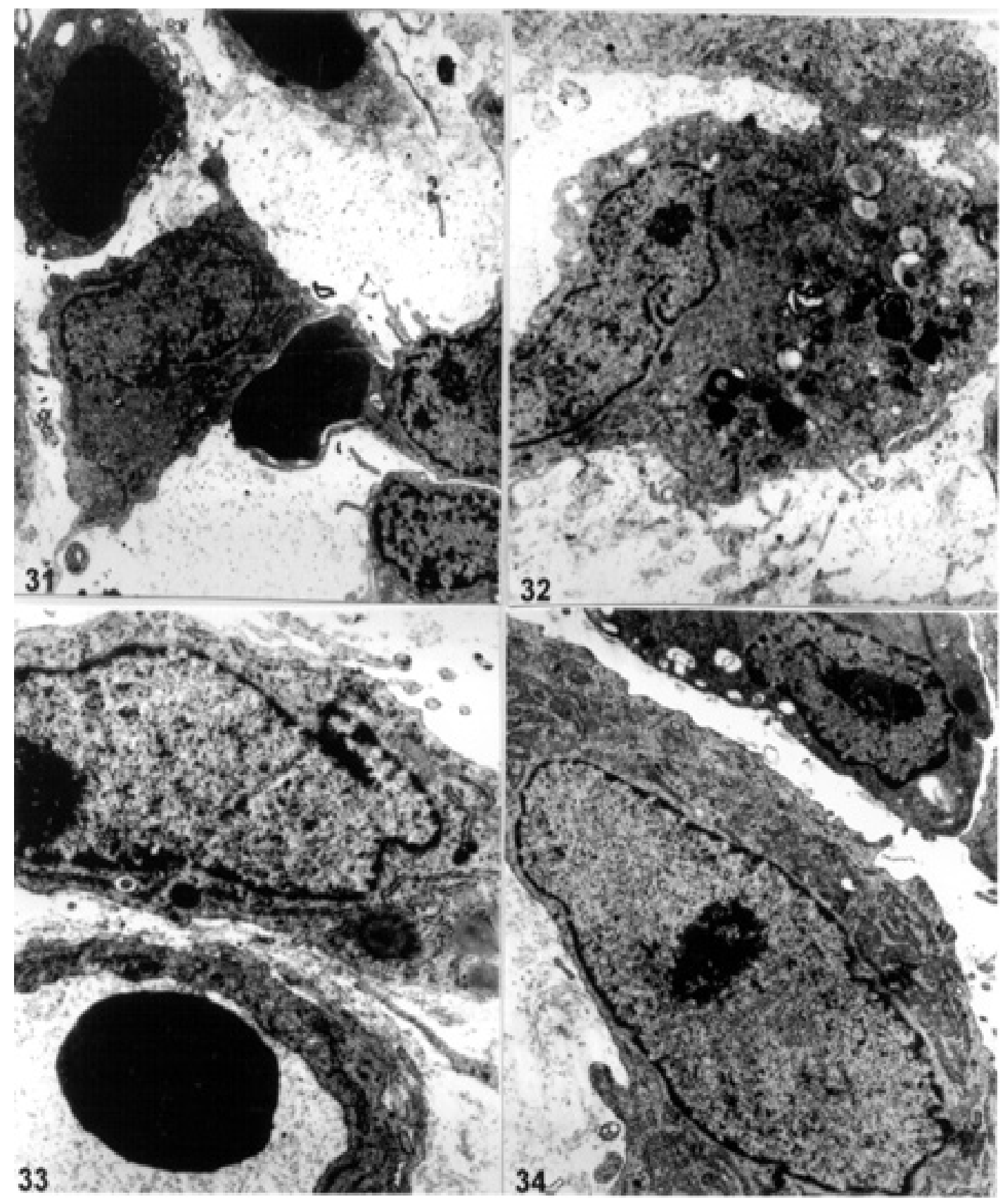

Fig. 31: erythrophagocytosis by three nodular macrophages. The cells are surrounded by proteoglycan particles (TEM, X 5,000). Fig. 32: macrophage presenting some myelinoid membranes and electron-dense iron-containing particles in the cytoplasm (TEM, X 5,000). Fig. 33: capillary, close to a fibroblast, partially surrounded by long processes of fibroblasts. The fibroblast contains electron-lucent and electron-dense lipid droplets (TEM, X 12,320). Fig. 34: active fibroblast with large and ovoid nucleus, heterochromatin in the periphery, nuclear pores easily visible and prominent nucleolus. The cytoplasm presents abundant rough endoplasmic reticulum. At the inferior-left corner, the fibroblast is in contact with tiny collagen fibers. The macrophage (at the top of the figure) shows several endocytic vacuoles at the periphery (TEM, X 11,140). 
VEGF in endothelial cells by products secreted by schistosome eggs (Loeffler et al. 2002).

The mesenchymal cells involved in the nodular fibrosis were characterized as fibroblasts and not as myofibroblasts due to the following aspects: they were negative for both alpha-smooth muscle actin and desmin and did not present by ultrastructural analysis folded or invaginated nucleus; abundant micropinocytotic vesicles; focal densities in the cytoplasm and a thin but usually distinct external lamina (Ghadially 1997).

There was inhibition or desintegration of the external muscular intestinal layer, where the nodules were located, without evidence of subsequent modification of the smooth muscle cells to myofibroblast phenotype. The
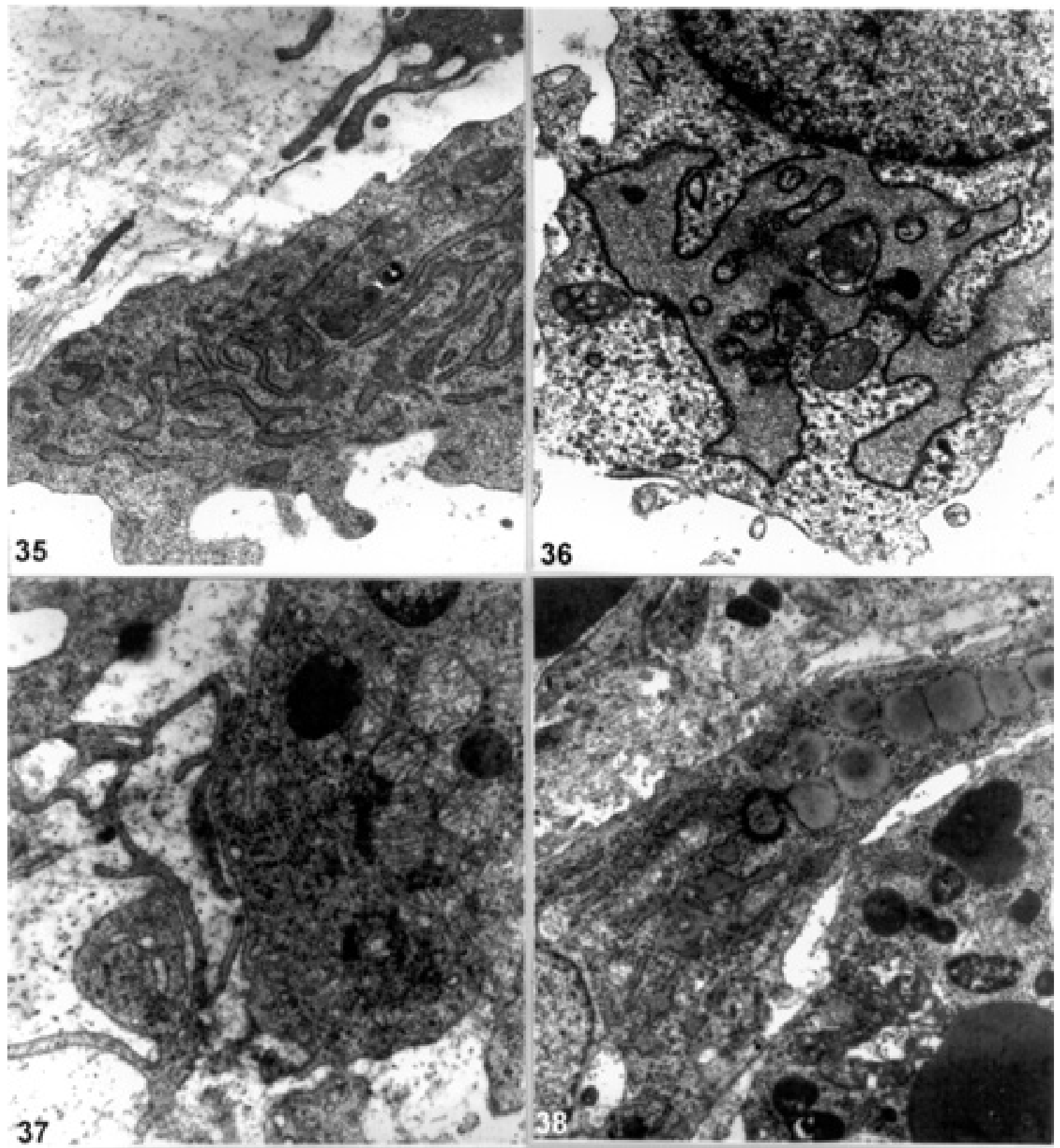

Fig. 35: part of fibroblast, with several arrays of rough endoplasmic reticulum. The adjacent extracellular matrix is composed by a delicate mesh of tiny fibers (TEM, X 16,000). Fig. 36: fibroblast showing dilated cisternae of rough endoplasmic reticulum and numerous small glycogen rosettes (TEM, X 20,000). Fig. 37: long processes of fibroblasts in close contact with macrophage rich in mitochondrias (TEM, $\mathrm{X}$ 125,000). Fig. 38: fibroblast presenting several electron-lucent lipid droplets in contact with a macrophage containg erythrocyte and electron-dense particles (TEM, X 10,000). 
large amount of carboxylated and sulfated glycosaminoglycans observed in the nodules could be an inhibiting factor on proliferation of smooth-muscle cells. Heparin and heparan sulfate glycosaminoglycans are potent inhibitors of vascular smooth-muscle cell proliferation in vivo and in vitro (Reilly 1993). Data from the literature indicate that heparin has no effect on platelet derived growth factor (PDGF) binding, but markedly inhibits the mitogenic response of smooth-muscle cells to this same factor and to epidermal growth factor (EGF) (Reilly 1993).

El-Awady et al. (2001) showed that $S$. hematobium SEA induced proliferation of human urothelial and bovine endothelial cells, but no effect was observed on smooth muscle cell lines.

Similar prominent intestinal fibrovascular nodules were also seen by Rodrigues-Silva (1989) in Nectomys squamipes, natural and experimentally infected with $S$. mansoni.

Portillo and Damian (1986) reported the presence of subserosal intestinal granulomatous nodules in a small New World monkey, the saddle-back tamarin Saguinus fuscicollis, subcutaneously infected with $150 \mathrm{~S}$. mansoni cercariae, which were necropsied at 18 months. According to these authors, the nodules may represent a defensive response to the thin-walled intestine of the tamarin monkeys to the presence of a large number of sequestered eggs. Nodules that contained eggs were also found free in the peritoneal cavity, where they had become necrotic. Such apparent budding off of heavily egg-infiltrated tissues may represent an even more pronounced type of sequestration (Portillo \& Damian 1986). Subserosal nodules resulting from confluent granulomas have been reported in humans and experimental animals with chronic S. mansoni infections (Kean \& Dennis 1971, Marcial-Rojas 1971).

It is important to point out that the fibrovascular nodules in C. callosus are different and larger than the granulomatous nodules observed by Domingo and Warren (1969) in Swiss albino female mice, studied after infection of $S$. mansoni for a period of 20 weeks and are also not directly related to local deposits of large number of eggs. On the contrary, in C. callosus model, there is a striking dissociation between the number of eggs per nodule and the pronounced perigranulomatous fibrovascular reaction. In this sense, pathologists have also been intrigued by large fibrous tumors caused by S. japonicum infection (bilharziomata) containing relatively few eggs (Lichtenberg et al. 1971).

In conclusion, the intestinal nodules in $C$. callosus are fibrovascular structures stimulated by local granulomas close to the serosa. They constitute an excellent and accessible model to study fibrogenesis and angiogenesis dependent on S. mansoni eggs. The fibrogenic activity is fibroblastic and not myofibroblastic-dependent. The angiogenesis is so prominent that causes haemorrhagic ascites. At least, in this model, the hypervascularity does not reflect inflammatory vasodilatation of preexisting host vessels, but is the outcome of angiogenesis.

This model allows investigating the following questions: (1) What are the local factors that simultaneously stimulate fibrous and vascular proliferation? Both events occur concomitantly in the human schistosomiasis, validating the importance of this experimental model; (2) What is the participation of mesothelial cells in this type of intestinal fibrosis and angiogenesis? (3) What are the local epigenetic factors involved in the angiogenesis-granuloma dependent, i.e., why this angiogenesis is not universally expressed in all the organs with schistosomal granulomas? (4) Do the inhibitors of angiogenesis interfere on fibrogenesis process?

\section{REFERENCES}

Alexander CM, Werb Z 1991. Extracellular matrix degradation. In ED Hay, Cell Biology of Extracellular Matrix, Plenum Press, New York, p. 255-302.

Andrade ZA 1965. Hepatic schistosomiasis: morphological aspects. In H Popper, F Schaffner (eds), Progress in Liver Disease, Grune \& Stratton, New York, p. 228-242.

Andrade ZA, Cheever AW 1971. Alterations of the intrahepatic vasculature in hepatosplenic schistosomiasis mansoni. Am J Trop Med Hyg 20: 425-432.

Azizkhan RG, Azizkhan JC, Zetter BR, Folkman J 1980. Mast cell heparin stimulates migration of capillary endothelial cells in vitro. $J$ Exp Med 152: 931-944.

Bogliolo L 1954. Sobre o quadro anatômico do fígado na forma hepato-esplênica da esquistossomose mansônica. Hospital (Rio de Janeiro) 45: 283-306.

Bogliolo L 1957. The anatomical picture of the liver in hepatosplenic schistosomiasis mansoni. Ann Trop Med Parasitol 51: 1-14.

Carson FL, Martin JH, Lynn JA 1973. Formalin fixation for electron microscopy: a re-evaluation. Am J Clin Pathol 59: 365-373.

Cheever AW 1987. Comparison of pathologic changes in mammalian hosts infected with Schistosoma mansoni, $S$. japonicum and S. haematobium. Mem Inst Oswaldo Cruz. 82 (Suppl. IV): 39-45.

Dolber PC, Spach MS 1993. Conventional and confocal fluorescence microscopy of collagen fibers in the heart. $J$ Histochem Cytochem 41: 465-469.

Domingo EO, Warren KS 1969. Pathology and pathophysiology of the small intestine in murine schistosomiasis mansoni, including a review of the literature. Gastroenterology 56: 231-240.

El-Awady MK, Gad YZ, Wen Y, Eassawi M, Effat L, Amr KS, Ismai S, Christ GJ 2001. Schistosoma hematobium soluble egg antigens induce proliferation of urothelial and endothelial cells. World J Urol 19: 263-266.

Folkman J, Taylor S, Spillberg C 1983. The role of heparin in angiogenesis. In Ciba Foundation Symposium, Development of the Vascular System, Pitman, London, p. 132-149.

Freedman DO, Ottesen EA 1988. Eggs of Schistosoma mansoni stimulate endothelial cell proliferation in vitro. J Infect Dis 158: 556-562.

Ghadially FN 1997. Ultrastructural Pathology of the Cell and Matrix, 4th ed., Buttterworth-Heinemann, Boston, 1414 pp.

Goldsmith HS 1996. Omental transposition for Alzheimer's disease. Neurol Res 18: 103-108.

Gomez E, Corrado OJ, Davies JR 1987. Histochemical and functional characteristics of the human nasal mast cell. Int Arch Allergy Appl Immunol 83: 52-56.

Grimaud JA, Borojevic R 1977. Myofibroblasts in hepatic schistosomal fibrosis. Experientia 33: 890-892.

Hudlická O, Tyler KR 1986. Angiogenesis. The Growth of the Vascular System, Academic Press, London, 221 pp.

Jackson JR, Seed MP, Kircher CH, Willoughby DA, Winkler, JD 1997. The codependence of angiogenesis and chronic 
inflammation. FASEB J 11: 457-465.

Junqueira LCU, Bignolas G, Brentani RR 1979. Picrosirius staining plus polarization microscopy, a specific method for collagen detection in tissue sections. Histochem J 11: 447-455.

Kean BH, Dennis DT 1971. The pathogenesis of junctional nodules in schistosomiasis. Bull Soc Pathol Exot 64: 84-95.

Laiho M, Keski-Oja J 1989. Growth factors in the regulation of pericellular proteolysis: a review. Cancer Res 49: 2533-2553.

Lenzi HL, Lenzi JA 1986. Swiss-roll technique examinations of intestines in experimental animals. Rev Soc Bras Med Trop 19 (Supl.): 106.

Lichtenberg F von, Sadun EH, Cheever AW, Erickson DG, Johnson AJ, Boyce HW 1971. Experimental infection with Schistosoma japonicum in chimpanzees. Am J Trop Med Hyg 20: 850-893.

Loeffler DA, Lundy SK, Singh KP, Gerard HC, Hudson AP, Boros DL 2002. Soluble egg antigens from Schistosoma mansoni induce angiogenesis-related processes by up-regulating vascular endothelial growth factor in human endothelial cells. J Infect Dis 185: 1650-1656.

Marcial-Rojas RA 1971. Pathology of Protozoal and Helminthic Diseases, William \& Wilkins, Baltimore, 373 pp.

Orlidge A, D'Amore PA 1987. Inhibition of capillary endothelial cell growth by pericytes and smooth muscle cells. J Cell Biol 105: 1455-1462.

Paraense WL, Corrêa LR 1963. Susceptibility of Australorbis tenagophilus to infection with Schistosoma mansoni. Rev Inst Med Trop São Paulo 5: 23-29.

Paraense WL, Corrêa LR 1981. Observations on two biological races of Schistosoma mansoni. Mem Inst Oswaldo Cruz 76: 287-291.

Popper H, Martin GR 1982. Fibrosis of the liver: The role of the ectoskeleton. In H Popper, F, Schaffner (eds), Progress in Liver Disease, Grune \& Stratton, London, p. 133-156.

Portillo HA del, Damian RT 1986. Experimental Schistosoma mansoni infection in a small New World monkey, the SaddleBack Tamarin (Saguinus fuscicollis). Am J Trop Med Hyg 35: 515-522.

Reilly CF 1993. Inhibition of smooth-muscle cell proliferation by heparin like molecules. In MA Zern, LM Reid (eds), Extracellular Matrix, M Dekker, Inc., New York, p. 429448.
Rheinwald JG 1989. Methods for clonal growth and serial cultivation of normal human epidermal keratinocytes and mesothelial cells. In R Baserga, Cell Growth and Division. A Practical Approach, IRL Press at Oxford University Press, Oxford, p. 81-94.

Rodrigues-Silva R 1989. Nectomys squamipes e Akodon arviculoides (Rodentia: Cricetidae) como Hospedeiros Naturais do Schistosoma mansoni em Sumidouro, RJ, Brasil. Emprego do Nectomys como Modelo Alternativo no Estudo da Esquistossomose Mansoni, MSc Thesis Fundação Oswaldo Cruz, Rio de Janeiro, 147 pp.

Saksela O, Rifkin DB 1988. Cell-associated plasminogen activation: regulation and physiological functions. Ann Rev Cell Biol 4: 93-126.

Schoefl GI 1963. Studies on inflammation III. Growing capillaries: their structure and permeability. Virchows Arch Pathol Anat Physiol 337: 97-141.

Shepro D, Morel NML 1993. Pericyte physiology. FASEB J 7: 1031-1038.

Smith RS 1961. The development of mast cells in the vascularized cornea. Arch Ophtalmol 66: 383-380.

Strobel S, Miller HRP, Ferguson A 1981. Human intestinal mucosa mast cells: evaluation of fixation and staining techniques. J Clin Pathol 34: 851-858.

Sunderkotter C, Steinbrink K, Goebeler M, Bhardwaj R, Sorg C 1994. Macrophages and angiogenesis. J Leuk Biol 55: 410422.

Vale BS, Pelajo-Machado M, Panasco MS, Lenzi JA, Lenzi HL 1997. Fluorescent stainings for mast cell and eosinophil study by confocal laser scanning microscopy. Cell Vision 4: 198-199.

Villaschi S, Nicosia RF 1994. Paracrine interactions between fibroblasts and endothelial cells in a serum-free co-culture model. Lab Invest 71: 291-299.

Zeillemaker AM, Mul FP, Hoynck-van-Papendrecht AA, Kuijpers TW, Roos D, Leguit P, Verbrugh H 1995. A polarized secretion of interleukin-8 by human mesothelial cells: a role in neutrophil migration. Immunology 84: 227-232.

Zhang QX, Magovern CJ, Mack CA, Budenbender KT, Ko W, Rosengart TK 1997. Vascular endothelial growth factor is the major angiogenic factor in omentum: mechanism of the omentum-mediated angiogenesis. J Surg Res 67: 147-154. 